\title{
POSITIO CONTRA COMPLEMENTUM POSSIBILITATIS - KANT AND BAUMGARTEN ON EXISTENCE ${ }^{1}$
}

\author{
Toni Kannisto, Oslo \\ Forthcoming in Kant-Studien (2015)
}

\section{Introduction}

Among the many accusations Kant levels at his predecessors, a central one is that they had misunderstood existence. Perhaps the most famous instance of this critique is Kant's contention that "[b]eing is obviously not a real predicate"2. Despite having been heavily discussed, Kant's claim has proved difficult to understand, and so the variety of competing interpretations remains great. To my mind, two factors above all have contributed to these difficulties. First, scholars have mostly analysed Kant's negative claims about what existence is not and given less attention to his positive thesis of what existence is - namely absolute positing. Second, also Kant's negative theses are regularly detached from their context as direct criticism of Alexander Baumgarten. Analysing Kant's negative theses against the Baumgartenian backdrop affords a better understanding both of them and of Kant's definition of existence as

\footnotetext{
${ }^{1}$ Quotations from Kant's works that have been translated to English are taken - with some alterations from the Cambridge Edition of the Works of Immanuel Kant (Cambridge, 1995 ff.). Other translations are mine.

${ }^{2} \mathrm{KrV}, \mathrm{A} 598 / \mathrm{B} 616$.
} 
absolute positing. Furthermore, it turns out that rather than being grounded on Kant's critique of Baumgarten, it is on the contrary Kant's novel positive definition of existence that originally grounds the negative anti-Baumgartenian theses.

Baumgarten's influence on Kant is considerable: not only did Kant use Baumgarten's Metaphysica ${ }^{3}$ - a systematisation and development of Christian Wolff's metaphysics ${ }^{4}$ - extensively in his lectures but he also utilised its terminology and shared many of its core tenets and structural features. Kant's relationship to Baumgarten is as close as it is ambivalent: Kant's harsh critique of Wolffian dogmatic rationalism, of which he saw Baumgarten as the perennial example, is contrasted with his generous suggestion that after his own critical framework has been laid down, the system of metaphysics could "readily" be completed "if one took the ontological textbooks in hand" ${ }^{\prime 5}$ - Metaphysica among them ${ }^{6}$. Kant's opinion of Baumgarten is perhaps laid most bare in an unpublished note from ca. 1776-1778, in which Kant characterises Baumgarten as "sharp-sighted (in small things) but not far-sighted (in big ones)" and goes on to add an entertaining remark about him being "a Cyclops among metaphysicians, who is missing one eye, namely critique". ${ }^{7}$

Although Baumgarten's importance to Kant is hardly a secret, it nonetheless remains relatively underappreciated. Baumgartenian terminology and influence runs deeper than is generally recognised. The two main sources for Kant's views on existence are his pre-critical The Only Possible Ground of a Prooffor the Existence of God from 1763 and the refutation of the ontological proof in the Critique of Pure Reason, both clearly written with Baumgarten in mind. As for existence, Baumgarten

\footnotetext{
${ }^{3}$ Baumgarten, Alexander Gottlieb: Metaphysica. Halle \& Magdeburg, ${ }^{4} 1757$ [1739]. In: AA 15 \& 17. Henceforth abbreviated as M. Translations from Latin are mine. I have consulted the two existing German translations, Metaphysik by Georg Friedrich Meier (Halle ${ }^{2} 1783$ [1766]), and the more recent bilingual Metaphysica / Metaphysik by Günther Gawlick \& Lothar Kreimendahl (Stuttgart, 2011). Metaphysica has also been translated into English as Metaphysics by Courtney D. Fugate and John Hymers (London, 2013).

${ }^{4}$ This metaphysics is presented above all in Wolff's Vernünfftige Gedancken von Gott, der Welt und der Seele des Menschen, auch allen Dingen überhaupt aka "Deutsche Metaphysik" (Halle, 1720) and Philosophia prima, sive ontologia (Frankfurt \& Leipzig, 1730)

${ }^{5} \mathrm{KrV}, \mathrm{A} 82 / \mathrm{B} 108$. Cf. KrV, A 204/B 249.

${ }^{6}$ Prol, AA 4: 325n.

${ }^{7}$ Refl. 5081, AA 18: 81f.
} 
is a particularly interesting philosopher, as he is credited for making precise Wolff's ${ }^{8}$ vague definition of existence as complementum possibilitatis - the complement of possibility - by explaining what existence adds to possibility to complement it. On this point Kant also specifically credits (and targets) Baumgarten:

\footnotetext{
Wolff's definition of existence, that it is a complement of possibility, is obviously very indeterminate. If one does not already know in advance what can be thought about possibility in a thing, one is not going to learn it from Wolff's definition. Baumgarten introduces the concept of thoroughgoing internal determination, and maintains that it is this which is more in existence than in mere possibility, for it complements that which is left indeterminate by the predicates inhering in or issuing from the essence. ${ }^{9}$
}

I will show that Kant does not oppose the idea per se that there is more in existence than in mere possibility, but Baumgarten's specific claim that existence would complement the possibility of a thing by determining its predicates further. Against this Wolffian-Baumgartenian complementum possibilitatis Kant pits his definition of being as positio - positing or setting. Rather than adding predicates to a thing, existence posits the thing itself with its predicates. In section 2 I will explicate Baumgarten's criterion, classification, and definition of existence. The aim of this section is not so much to contribute to Baumgarten scholarship than to set the stage for section 3 that shows how Kant formulates three corresponding negative theses to oppose Baumgarten. The structure of Kant's arguments show that these negative theses are dependent and grounded on his positive definition of existence as absolute positing, which I will then analyse in detail in section 4. All in all I seek to show that Kant's negative theses - including that being is not a real predicate - cannot in fact be adequately explicated and defended in isolation from his positive one, as is unfortunately commonly done. Focusing on the definition of being as positing yields a deeper understanding and a more solid defence of Kant's theory of existence.

\footnotetext{
${ }^{8}$ Wolff, Christian: Philosophia prima, sive ontologia, method scientifica pertractata, qua omnis cogitationis humanae principia continentur, Frankfurt am Main \& Leipzig, 1730, §174.

${ }^{9}$ BDG, AA 2: 76, translation altered.
} 


\section{Baumgarten on Existence}

The basic building block of Baumgarten's conception of existence is the concept of determination, a posited predicate:

Those (characteristic marks and predicates) that are posited in something through determining are DETERMINATIONS; the one positive and affirmative, $\S 34,10$, which if it truly is so, is a REALITY, the other negative, $\S 34,10$, which if it truly is so, is a NEGATION. ${ }^{10}$

Apart from realities and negations, there are two main types of determinations: inner and outer. ${ }^{11}$ The former are intrinsic, non-relational properties or aspects of things; the latter are relations.

According to Baumgarten, some of the inner determinations are primary and others secondary. Unlike the secondary determinations, the primary ones are not dependent on other inner determinations and are thus essential. ${ }^{12}$ Furthermore, for Baumgarten the "sum total ${ }^{13}$ [complexus, Inbegriff] of the essentials in a possible thing, or its inner possibility, is ESSENCE"14. Hence also a thing is possible if and only if its essential predicates do not contradict each other: its possibility rests on the consistency of its essence in accordance with the principle of contradiction (law of non-contradiction). ${ }^{15}$

The remaining (non-essential) inner determinations of things are grounded on the essential ones and are called affections or corollary determinations (affectiones, Folgebestimmungen). ${ }^{16}$ Baumgarten does not give examples of primary and corollary determinations, but presumably if something is human and thus instantiates the

\footnotetext{
10 "Quae determinando ponuntur in aliquo (notae et praedicata), sunt DETERMINATIONES, altera positiva, et affirmativa, $\S 34,10$, quae si vere sit, est REALITAS, altera negativa, $\S 34,10$, quae si vere sit, est NEGATIO.” (M, §36.)

${ }^{11} \mathrm{M}, \S 37$.

${ }^{12} \mathrm{M}, \S \S 39,41,50$.

${ }^{13}$ Since Inbegriff as the German equivalent of complexus is often translated in Kant's works as sum total, and since presumably these terms mean the same thing for Kant and Baumgarten, I have translated complexus as sum total - Fugate and Hymers translate it as collection.

14 "Complexus essentialium in possibili, seu possibilitas eius interna est ESSENTIA" (M, §40).

${ }^{15} \mathrm{M}, \S 8$.

${ }^{16} \mathrm{M}, \S 41$.
} 
essential predicates of, say, featherless and bipedal, then its corollary determinations are such as capable of running and unpluckable. Baumgarten divides corollary determinations further in two. Corollary determinations that are sufficiently grounded on essence are called attributes; those not sufficiently grounded on the essence (and hence partially determined by something else) are modes or accidental properties. ${ }^{17}$ That the sum of the angles of a triangle (in Euclidian plane) is 180 degrees is arguably its attribute, sufficiently grounded on its essence, whereas having a straight angle is a mode.

Figure 1: Baumgarten's classification of determinations

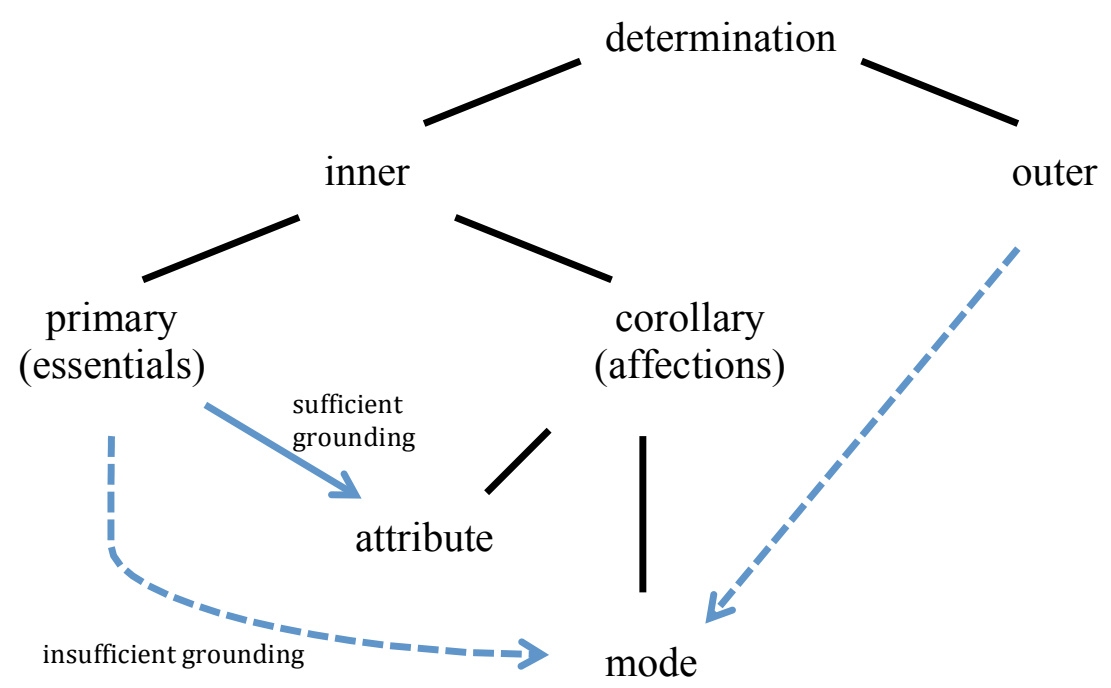

From these ingredients Baumgarten bakes his definition of existence:

EXISTENCE (act, cf. \$210, actuality) is the sum total of the corollary determinations compossible in a something, i.e. the complement of the essence or of the inner possibility, insofar as this [the essence or inner possibility] is considered only as a sum total of determinations. $^{18}$

\footnotetext{
${ }^{17} \mathrm{M}, \S 50$.

18 “EXSISTENTIA (actus, cf. $\$ 210$, actualitas) est complexus affectionum in aliquo compossibilium, i. e. complementum essentiae sive possibilitatis internae, quatenus haec tantum, ut complexus determinationum spectatur.” $(\mathrm{M}, \S 55$.)
} 
If not only the essence but also the corollary determinations of a thing are determined, then it exists, and so existence complements essence or inner ${ }^{19}$ possibility. Existing wombats differ from merely possible ones in that whereas possible wombats have determinate wombat essence and wombaty attributes, existing wombats have secondary properties, too: their specific size, age, location, the thickness of their fur, the specific make-up of their bacterial flora, etc. Hence all wombats are identical in their essence, and their difference lies in their existence. The idea is that actually existing things (usually) have more properties than can be derived from their mere possibility (essence), and thus these properties belong to their existence.

It is crucial that existence is defined as the complement of (inner) possibility not merely as something added to possibility. A complement involves the idea of a totality: something is completed through adding everything that is missing from it. ${ }^{20}$ Thus Baumgarten can present thoroughgoing (inner) determination as the criterion of existence: that which is determined with regard to all its compossible predicates, exists. ${ }^{21}$ Merely possible wombats are not thoroughly determined because it remains undetermined whether they are big or small, young or old, etc. - and such determinations are required for complete wombats. Since such secondary determinations are grounded on and given in existence, any thoroughly determined being must exist.

Furthermore, Baumgarten counts existence among the determinations of things, as a determination that adds positive (rather than negative) properties to things. He thus classifies existence as a reality or real predicate ${ }^{22} \cdot{ }^{23,24}$ Hence, importantly,

\footnotetext{
${ }^{19}$ External possibility depends on outside forces and circumstances and is not very relevant for the discussion at hand $(\mathrm{M}, \S 16)$.

${ }^{20}$ This only includes the internal determinations, not any external relations. Cf. note 19.

${ }^{21} \mathrm{M}, \S \S 54,148,152$.

${ }^{22}$ A real predicate adds to (rather than subtracts from) "the concept of a thing" (KrV, A 598/B 626) and is hence positive (not negative) determination, a reality.

${ }^{23} \mathrm{M}, \S \S 36,66,135,810$.

${ }^{24}$ Since Baumgarten defines existence as the complement of essence or the sum total of corollary determinations, not as any particular determination, one might question whether existence itself can be a reality, predicate, or determination. Yet Baumgarten does explicitly say that "existence is a reality" (M, §810; cf. M, §66), and realities are determinations of things (hence real predicates) (M, §36). Although Baumgarten's peculiar view and the ambiguity in it therefore warrant analysis, I will not assess it further here. For the main goal of this paper - to explicate Kant's theory of existence - it
} 
existence is on par with other predicates and so complements possibility by adding something akin to the predicates things have in virtue of their possibility - rather than something wholly different. Existence does not determine the predicates from the outside, as it were, but by itself being one of the predicates. This is ultimately required for the ontological argument: only if existence is a reality capable of being counted among essential determinations can the mere (inner) possibility and essence of God as the most perfect being contain its existence.

\section{Kant's Critique of Baumgarten}

We have seen that Baumgarten characterises existence in three ways. He (E1+) sets thoroughgoing determination as the criterion of existence, he (E2+) classifies existence as a reality - a positive determination of a thing - and he $(\mathrm{E} 3+)$ defines existence as the complement of inner possibility or essence. For Kant there is something correct and something false in all three. First, although Kant agrees that every existing being is necessarily thoroughly determined, he does not grant that conversely every thoroughly determined being exists. Thus he (E1-) rejects thoroughgoing determination as the criterion (necessary and sufficient condition) of existence. Second, although for Kant existence qualifies as a logical predicate in that it can be used as a predicate in a judgment, (E2-) it cannot be classified as a reality (real predicate) because it does not add any determinations to things. Third, for Kant, too, existence does add something to possibility: "[t] hrough the actuality of a thing I certainly posit more than possibility"25. But contra Baumgarten, (E3-) existence cannot complement the possibility of a thing by adding to its predicates, since $(\mathrm{E}+)$ it rather adds the thing itself with its predicates - posits it absolutely. Furthermore, as I will show, Kant rejects Baumgarten's criterion of existence because he rejects his classification of it, and he does so because he denies Baumgarten's definition of existence, for he takes himself to have proven his own definition of existence. Kant's argument thus runs from the positive thesis to the negative ones, not vice versa.

suffices to show that Baumgarten did take existence to be both the sum total of corollary determinations and a determination in its own right - irrespective of how tenable his view may be.

${ }^{25} \mathrm{KrV}$, A 234/B $287 \mathrm{n}$. 


\subsection{Existence And Thoroughgoing Determination}

Faced with Baumgarten's definition of existence, one might ask what he thinks of very determinate yet merely possible entities, such as the possible invisible unicorn that is dancing on my head right now, that weighs 0.87 kilos, is called Bob, and has a brother called Rob, who incidentally is dancing next to Bob to the same tune - namely Cream by Prince. Surely making up more and more determinate entities does not contribute to their existence, so why would thoroughgoing determination fare any better? Indeed, this is a concern that Kant voices:

[T] he proposition that a possible thing, regarded as such, is indeterminate with respect to many of its predicates, could, if taken literally, lead to serious error. For such indeterminacy is forbidden by the law of excluded middle which maintains that there is no intermediate between two predicates which contradict each other. It is for example impossible that a man should not have a certain stature, position in time, age, location in space, and so forth. Our proposition must rather be taken in the following sense: the predicates which are thought together in a thing in no way determine the many other predicates of that thing. Thus, for example, that which is collected together in the concept of a human being as such specifies nothing with respect to the special characteristics of age, place, and so forth. But then this kind of indeterminacy is to be found as much in an existent thing as it is in a merely possible thing. For this reason, it cannot be used to distinguish the two. ${ }^{26}$

That I am a man does not determine the colour of my eyes - this is a fact that pertains also when I exist, not just where my possibility is concerned. Even worse for Baumgarten, since the law of excluded middle dictates that, necessarily, a thing either is blue-eyed or not, in fact only thoroughly determined beings are possible (can exist) at all - regardless of whether our thought of them is indeterminate or not. And so Kant rejects Baumgarten's criterion of existence: how many predicates one latches onto a concept and however independent some of its predicates are from others has nothing to do with whether its object exists. It does appear that Baumgarten is conflating the fact that in existence those properties are determined that are not determined by the essence with thoroughgoing determination thereby counting as a criterion of existence. But although thoroughgoing determination is according to Kant

\footnotetext{
${ }^{26} \mathrm{BDG}, \mathrm{AA} 2: 76$.
} 
a necessary condition of existence, since existing beings must be thoroughly determinate, it is not its sufficient condition. ${ }^{27}$ Kant exemplifies this as follows:

Take any subject you please, for example, Julius Caesar. Draw up a list of all the predicates which may be thought to belong to him, not excepting even those of space and time. You will quickly see that he can either exist with all these determinations, or not exist at all. The Being who gave existence to the world and to our hero within that world could know every single one of these predicates without exception, and yet still be able to regard him as a merely possible thing which, in the absence of that Being's decision to create him, would not exist. ${ }^{28}$

Kant's criticism is not limited to very determinate concepts but applies also to completely determinate ones - such as God. Kant says this very explicitly in the Critique: "If the concept of a thing is already entirely complete, I can still ask about this object whether it is merely possible, or also actual" 29 . Indeed, importantly, Baumgarten uses his criterion of existence to prove the necessary existence of God. ${ }^{30}$ The gist of this proof is that God as a self-sufficient perfect being has no modes or accidental properties, only essential properties and attributes that logically follow from them. Hence, grounded on its very essence, God's properties are thoroughly determined, and so God exists in virtue of its mere possibility, i.e., necessarily. ${ }^{31}$ This is, of course, an ontological argument, and it fails for a familiar reason: since, as we will see, existence is not a predicate that could contribute to the thoroughgoing determination, even if God's concept is thoroughly determined, its object need not exist.

\footnotetext{
${ }^{27}$ E.g. V-Met-L2/Pölitz, AA 28: 554; HN, AA 23: 32. Cf. also Kant's rejection of the inference from the thoroughgoing determination of the ens realissimum to its existence ( $\mathrm{KrV}, \mathrm{A} 580 / \mathrm{B} 608)$.

${ }^{28}$ BDG, AA 2: 72.

${ }^{29} \mathrm{KrV}$, A 219/B 266.

${ }^{30} \mathrm{M}, \S \S 110-2,810,823-4$.

${ }^{31}$ This agrees with Kant's definition of necessity: "necessity is nothing other than the existence that is given by possibility itself” (KrV, B 111). Cf. V-Met-L2/Pölitz, AA 28: 554.
} 


\subsection{Existence as Predicate}

Kant grants that existence can function as predicate, but only with significant restrictions. Already in his 1763 essay, after criticising the idea that if something exists, it would "contain an extra predicate",32, Kant notes:

Nonetheless, the expression "existence" is used as a predicate. And, indeed, this can be done safely and without troublesome errors, provided that one does not insist on deriving existence from merely possible concepts, as one is accustomed to doing when one wants to prove absolutely necessary existence. ${ }^{33}$

The relevant issue is not whether existence can be used as a predicate but whether it is a predicate in such a way as to support the ontological proof. Kant makes this point in the Critique by distinguishing between logical and real predicates:

Anything one likes can serve [i.e. be used] as a logical predicate, even the subject can be predicated of itself; for logic abstracts from every content. But the determination is a predicate that goes beyond the concept of the subject and enlarges it. Thus it must not be contained in it already. ${ }^{34}$

To complete God (as a thing), existence would have to be such a Baumgartenian determination, i.e. a real predicate of a thing (M, §36; KrV, A 598/B 626). A logical predicate is simply something that holds the logical place of $B$ in the categorical judgment " $\mathrm{A}$ is $\mathrm{B}$ " (the logical subject is $A$ ). Although existence can for Kant be treated as a logical predicate by putting it in the logical place of predicate e.g. in "God is existing," it is not a real predicate or a determination of a thing. Rather:

Strictly speaking, the matter ought to be formulated like this: "Something existent is God". In other words, there belongs to an existent thing those predicates which, taken together, we designate by means of the expression "God". 35

\footnotetext{
${ }^{32}$ BDG, AA 2: 72 .

${ }^{33}$ Ibid.

${ }^{34} \mathrm{KrV}$, A 598/B 626, translation altered.

${ }^{35}$ BDG, AA 2: 74.
} 
That God's concept is complete, that its essence and attributes are thoroughly determined, and that 'God' hence denotes the perfect or the most real being - none of these is what Kant disputes. Rather, he only denies that this would have any bearing on whether God exists. Existence is not one of the real predicates; it denotes their instantiation. Thus the judgment " $\mathrm{A}$ is existent" does not mean that the determination 'existence' is predicated of $A$ but that some thing $a$ instantiates all the predicates of $A$. To see why, we must analyse Kant's claim that - unlike determinations - existence adds nothing to the content of either the thing $a$ or its concept $A$.

\subsection{Existence and Content}

Like above, although Kant does agree with Baumgarten that existence adds something to possibility, he disagrees on the way in which existence is supposed to add to or complement possibility. One should not fail to notice Kant's repeated qualifications in his critique of the complementum possibilitatis, e.g.: "Through the actuality of a thing I certainly posit more than possibility, but not in the thing; for that can never contain more in actuality than what was contained in its complete possibility." ${ }^{, 36,37}$ For Baumgarten it is exactly the thing or its content that is supposedly amplified by further properties when one moves from possibility to actuality. ${ }^{38}$ Kant on the contrary never tires of reiterating that although to be sure through existence something is added to mere possibility, nothing at all is added to the thing, and so it will thereby contain nothing more. Rather, it is the thing itself that gets added. Or as Kant puts it in 1763:

[A] distinction must be drawn between what is posited and how it is posited. As far as the former is concerned: no more is posited in an actual thing than is posited in a merely possible thing, for all the determinations and predicates of the actual thing are also to be found in the

\footnotetext{
${ }^{36} \mathrm{Kr} V$, A $234 \mathrm{f} . / \mathrm{B} 287 \mathrm{n}$.

${ }^{37}$ According to an objection voiced against my view, Kant allegedly only attributes content to the representation or a concept of a thing, not to the thing itself. But the cited passage and numerous others explicitly attribute content to a thing, not its representation. In the present section I exactly seek to show that and how Kant can consistently do so - or, in light of his arguments, indeed has to do so.

${ }^{38} \mathrm{M}, \S 61$.
} 
mere possibility of that same thing. However, as far as the latter [the 'how'] is concerned: more is posited through actuality [...], for positing through an existent thing involves the absolute positing of the thing itself as well. ${ }^{39}$

The distinction Kant draws is not between adding and not adding more but between positing more in a thing and through a thing. To better understand this important distinction, consider Kant's (in)famous example of possible and actual dollars:

\begin{abstract}
A hundred actual dollars do not contain the least bit more than a hundred possible ones. For since the latter signifies the concept and the former its object and its positing in itself, then, in case the former contained more than the latter, my concept would not express the entire object and thus would not be the suitable concept of it. ${ }^{40}$
\end{abstract}

Although Kant is quick to remark that "in my financial condition there is more with a hundred actual dollars than with the mere concept of them (i.e., their possibility)" ${ }^{41}$, his point has proven difficult to surmise. I suggest that the key to understanding it lies in the concept of containment - a commonly overlooked but ubiquitous term in Kant's treatment of existence. ${ }^{42}$ What does it mean that actual dollars do not "contain" more than possible ones? In Jäsche Logik Kant defines content and contrasts it with extension:

Every concept, as partial concept, is contained in the representation of things; as ground of cognition, i.e., as mark, these things are contained under it. In the former respect every concept has a content $[$ Inhalt $]$, in the other an extension $[\text { Umfang }]^{43}{ }^{44}$

Kant's distinction is similar (albeit not identical) to the contemporary one between intension and extension. The content of a concept is the set of partial concepts that

\footnotetext{
${ }^{39} \mathrm{BDG}, \mathrm{AA}$ 2: 75, my emphasis.

${ }^{40} \mathrm{KrV}$, A 599/B 627.

${ }^{41}$ Ibid.

${ }^{42}$ The concept of 'content' is analysed by some scholars (e.g. Stuhlmann-Laeisz, Rainer: Kants Logik. Berlin, 1976; Prien, Berndt: Kants Logik der Begriffe. Berlin, 2006) and is commonly featured in discussions about analytic and synthetic judgments. Yet its role in Kant's philosophy of existence is seldom noted or utilised.

${ }^{43}$ Kant also identifies Umfang with Sphäre, 'sphere' (e.g. Log, AA 9: 96).

${ }^{44} \log$, AA 9: 95.
} 
make up its thought-content, like the concept of bachelor contains the concepts man and unmarried. The extension of a concept is the set of things to which it refers, e.g. all things that instantiate the concepts of man and unmarried.

Let us denote the intension/content of the concept of an object $A$ by the set $A_{I}$ $=\left\{\mathrm{P}_{1}, \mathrm{P}_{2}, \ldots, \mathrm{P}_{\mathrm{n}}\right\}$, where $P_{1}, \ldots, P_{n}$ are all the predicates that as partial concepts make up $A$ 's thought-content. ${ }^{45}$ Similarly, let the extension of the concept $A$ be the set $A_{E}=$ $\left\{\mathrm{a}_{1}, \mathrm{a}_{2}, \ldots, \mathrm{a}_{\mathrm{m}}\right\}$, where $a_{1}, \ldots, a_{m}$ are all the things that instantiate $A_{I}$. As is standard, $A_{I}$ determines $A_{E}$ in the sense that the members of $A_{E}$ are selected based on the predicates of $A_{I}$ (equally standardly, for Kant $A_{E}$ still cannot be inferred from $A_{I}$ ).

But what could Kant mean by the "content" of actual (AD) and possible dollars (PD)? After all, things do not have an intension, only their concepts. Kant employs the term 'content' in various ways but - as far as I can tell - never explains this particular use. Yet the expression does make sense if he means this: All entities in $A D_{E}$ and $P D_{E}$ instantiate the same predicates (those of dollars, i.e. $D_{I}$ ) in virtue of constituting the extension of $D$. Thus, unlike today's intension, for Kant content can be (and is) attributed also to things: the content of $A_{E}$ is the set of predicates instantiated by all its members in virtue of belonging to the extension corresponding to $A_{I}$. In contemporary terms, the content of $A_{E}$ is the set of properties (instantiated predicates) determined by the set of predicates $A_{I}$. The content of dollars is the set of properties they have in virtue of being referents of the concept of dollar. Importantly, and obviously, they can (and do) also have other properties in virtue of being referents of other concepts as well - say, of 'smudgy' for smudgy dollars specifically.

There are, then, two senses in which a thing may instantiate predicates. In Kant's technical sense a thing contains the predicates it has in virtue of being a referent of a concept. Thus it shares these predicates with all other such referents (in this sense of containment, wombats contain all predicates of wombatness, no more, no less). In another (more contemporary) sense the referent of a concept may instantiate (or contain) a plethora of other predicates that have nothing (or little) to do with this concept (wombats may be female, spray-painted pink, or suffer from pneumonia these properties wombats have only in virtue of being referents of other concepts than

\footnotetext{
${ }^{45}$ I do not here wish to imply that the set of predicates belonging to the intension of a thing has to be finite. I only present the finite version for the sake of clarity in what would otherwise become a needlessly cumbersome formal presentation.
} 
'wombat'). It is always in the former sense that according to Kant existence adds nothing (no content) to things or their concepts. If existence added such content, "A exists" would change the intension of $A$ rather than asserting that a non-empty extension $A_{E}$ corresponds exactly to this intension $A_{I}$.

Now, let us assume that the existence-predicate $E$ belongs to the content of $A_{E}$. Then either $A_{I}$, too, contains $E$ or not. If it did, then the absurdity would follow that existence would belong to the thought-content or intension of all concepts whose objects exist - e.g. wombats would exist by definition. This is also met with Kant's objection that "[y]ou have already committed a contradiction when you brought the concept of its existence [...] into the concept of a thing which you would think merely in terms of its possibility [through its concept]" ${ }^{, 46}$. If, on the other hand, $E$ did not belong to $A_{I}$, then the content of $A_{E}$ would not match $A_{I}$, which, however, would contradict the idea that $A_{I}$ determines $A_{E}$ and its content. This is why in the passage cited above (KrV, A 599/B 627) Kant points out that "in case the [object of the concept] contained more than the [concept], my concept would not express the entire object and thus would not be the suitable concept of it". Hence, unhappily for Baumgarten, if existence were a predicate capable of contributing to the content of a thing (a real predicate), either the concepts of all things that happen to exist (not just God) would have existent objects in virtue of their meaning or it would be impossible for any concept to adequately refer to its object.

This analysis also allows Kant to avoid a serious and famous objection ${ }^{47}$. The concept of wombat, for instance, refers both to jacks and jills - male and female wombats. But since the intension of 'wombat' does not contain the predicate 'female,' objects of concepts can instantiate a myriad of predicates not contained in or determined by the intensions of their concepts - so why could not actual dollars instantiate the predicate of existence in addition to all the predicates contained in their concept $?^{48}$ Like some wombats are jacks and some jills, maybe some wombats are

\footnotetext{
${ }^{46} \mathrm{KrV}, \mathrm{A} 597 / \mathrm{B} 625$.

${ }^{47}$ Cf. Bennett, Jonathan: Kant's Dialectic. Cambridge 1974, 230.

${ }^{48}$ Note that Kant is aware of this point and actually uses it against Baumgarten's attempt to make thoroughgoing determination the criterion of existence: "It is for example impossible that a man should not have a certain stature, position in time, age, location in space, and so forth. [...] Thus, for example, that which is collected together in the concept of a human being as such specifies nothing with respect to the special characteristics of age, place, and so forth." (BDG, AA 2: 76.)
} 
possible and some actual. However, this has nothing to do with Kant's actual claim that the referent thing contains exactly the same predicates as the intension of its concept in the technical sense of containment just explicated. $A_{E}$ contains the predicates instantiated by all its members, not just by some of them, and thus although all humans have a size (contained in the concept of humans as bodily things), they might all instantiate a different size (the specific size is not contained in humans as things).

The Jack \& Jill Objection disregards the finesse of Kant's claim about actual and possible dollars and so comes down to this uncontroversial and unproblematic point: things can be objects of several concepts. This Kant can readily grant: an individual wombat could belong to the extension of e.g. 'wombat,' 'female,' and 'furry.' The specific set of concepts to the extension of which the wombat belongs can distinguish it from other wombats, yet the wombat is an object or referent of each concept only because it instantiates its predicates precisely and thereby shares these predicates with all other objects of that kind (here: all females and furry things). In no way does this touch Kant's point that existence adds nothing to things and is therefore not a real predicate.

Baumgarten could also not avoid Kant's criticism by taking existence as a special predicate that is always instantiated by existing things irrespective of their content, for this move would undermine his attempt to prove the existence of God using thoroughgoing determination, as it would constitute the admission that a concept could never contain the predicate of existence even if all existing things would have to instantiate it. Indeed, it would only serve to cede Kant's point that whatever existence adds to things, it does not add a determination of the kind that constitutes their essence, and so Baumgarten's classification and definition of existence fail. Consider the following passage from this point of view:

\footnotetext{
Thus when I think a thing, through whichever and however many predicates I like (even in its thoroughgoing determination), not the least bit gets added to the thing when I posit in addition that this thing is. For otherwise what would exist would not be the same as what I had thought in my concept, but more than that, and I could not say that the very object of my concept exists. [...] Now if I think of a being as the highest reality [i.e. God] (without defect), the question still remains whether it exists or not. ${ }^{49}$
}

\footnotetext{
${ }^{49} \mathrm{KrV}, \mathrm{A} 600 / \mathrm{B} 628$.
} 
Kant's target is Baumgarten (and like-minded philosophers): even in its thoroughgoing determination, our concept could neither contain nor therefore entail the existence of its object, and whatever existence adds to possibility, it cannot be a real predicate contributing to the content of either concepts or their objects and so complement their essence - and thus the ontological proof fails along with Baumgarten's definition of existence as complementum possibilitatis. The three negative theses are therefore intimately connected: (E1-) thoroughgoing determination cannot ground existence because existence is not one of the determinations, and it is not one of them because (E2-) it is not a real predicate or a determination of things at all, and this is so because (E3-) it does not add anything into things and so cannot complement their essence. These three negative theses are ultimately grounded on the positive one, for existence cannot add anything into things exactly because (E+) it rather posits the thing itself.

\section{Existence as Absolute Positing}

The concept of positing may be difficult to understand. The simple (if not easily graped) definition of it Kant gives already in his 1763 treatise:

\footnotetext{
The concept of positing or setting is perfectly simple: it is identical with the concept of being in general. Now, something can be thought as posited merely relatively, or, to express the matter better, it can be thought merely as the relation (respectus logicus) of something as a characteristic mark to a thing. In this case, being, that is to say, the positing of this relation, is nothing other than the copula in a judgment. If what is considered is not merely this relation but the thing posited in and for itself, then this being is the same as existence. ${ }^{50}$
}

Kant also characterises (actual) existence as absolute positing in contrast to relative positing. ${ }^{51}$ The former is the simple positing of a thing with its predicates; the latter is

\footnotetext{
${ }^{50}$ BDG, 73, translation altered. Note that Baumgarten's respectus denotes "relations in the wider sense" (M, §37). Respectus logicus is a logical relation, which involves determining something with regard to something else: “A is B.” Because Kant shares Baumgarten's terminology, I opt for a more consistent translation of Beziehung as 'relation' rather than 'respect.'

${ }^{51}$ E.g. V-Met-L2/Pölitz, AA 28: 552; V-Met/Mron, AA 29: 822; Longuenesse, Béatrice: Kant's Capacity to Judge. Princeton 1998, 352.
} 
its positing in relation to further predicates. I.e., in relative positing predicates are posited to the subject, whereas absolute positing posits the subject itself. The distinction between the two uses of "is" in " $\mathrm{A}$ is" and " $\mathrm{A}$ is $\mathrm{B}$ " is very helpful:

\begin{abstract}
Being is obviously not a real predicate, i.e., a concept of something that could add to the concept of a thing. It is merely the positing of a thing or of certain determinations in themselves. In the logical use it is merely the copula of a judgment. The proposition God is omnipotent contains two concepts that have their objects: God and omnipotence; the little word 'is' is not a predicate in it, but only that which posits the predicate in relation to the subject. Now if I take the subject (God) together with all his predicates [...], and say God is, or there is a God, then I posit no new predicate to the concept of God, but only posit the subject in itself with all its predicates, and indeed posit the object in relation to my concept. Both must contain exactly the same, and hence when I think this object as given absolutely (through the expression, 'it is'), nothing is thereby added to the concept that expresses merely its possibility. ${ }^{52}$
\end{abstract}

Neither in the relative positing of "A is B" nor in the absolute positing " $\mathrm{A}$ is" does the 'is' - pace Baumgarten - determine a further predicate of the thing. In its logical use, being denotes that the predicate $B$ is part of $A-B$ is posited or added to the content of A. As Béatrice Longuenesse has pointed out, the relative positing through the logical 'is' denotes predication. ${ }^{53}$ Rather than a predicate, the copula is that which connects the predicate to the subject. In its real or absolute use, being expresses the idea that $A$ - with whatever predicates it contains - exists, i.e., that some thing instantiates these predicates. Here, too, the role of the 'is' is to connect one thing with another, this time not the predicate $B$ with another predicate $A$, but the subject term $A$ itself, together with its predicates, with its referent thing.

As we have seen, for Kant existence does not add to the concept of a thing so as to add to its content or intension. It does, however, add something to possibility, namely extension. What gets posited is not something additional in the thing, but the thing itself, or: "[w]ith actuality, the object is added to a concept, but nothing is added to the object" "54. "Wombats exist" does not add new properties to wombats but states that the concept of wombat (with its wombaty predicates) refers to some things, i.e.,

\footnotetext{
${ }^{52} \mathrm{KrV}$, A 598/B 626 f., translation altered, cf. note 50 .

${ }^{53}$ Longuenesse, Béatrice: Kant and the Capacity to Judge. Princeton 1998, 352.

${ }^{54}$ Mron, AA 29: 822.
} 
that some things instantiate all the predicates expressed by the concept of wombat. No content is added to the concept - hence its meaning is not altered - but rather it is added that it has an actual object. To summarise, actuality is more than possibility, but it does not contain more than possibility.

There is a vast difference between saying that a thing $a$ instantiates the predicate $A$ and adding another predicate $B$ to $A$ (and to $a$ through $A$ ). And if the former is what existence as absolute positing does, then it is fairly obvious that existence and essence belong to fundamentally different strata. One could say that if adding a predicate to $A$ in " $\mathrm{A}$ is $\mathrm{B}$ " is horizontal, then positing $A$ as existing in "A is" is vertical:

\section{Figure 2: Absolute and relative positing}

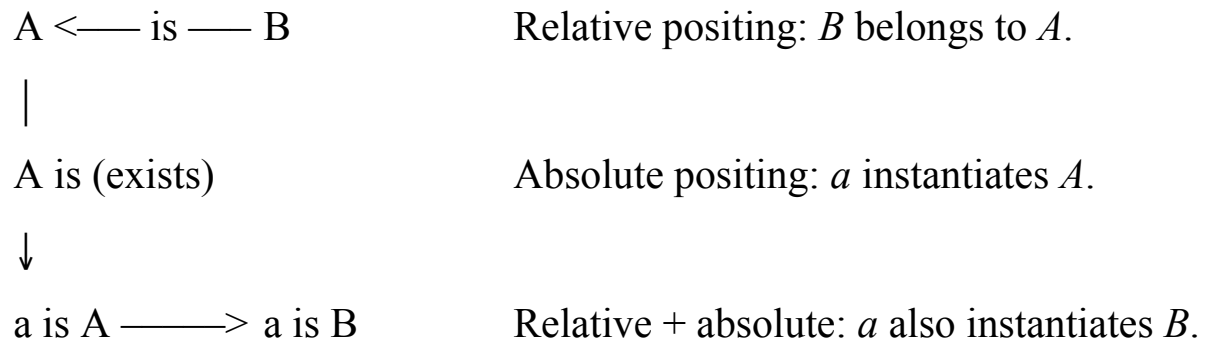

Here relative positing adds the predicate $B$ to the subject $A$ but does not concern the (possible) existence of $A$. This existence is added via the absolute positing of $A$, which determines some thing $a$ as instantiating the predicates of $A$. Together the two kinds of positing determine $a$ as also instantiating $B .^{55}$

The term 'positing' is not Kant's invention, however. Quite the contrary, Baumgarten for one makes extensive use of it. Baumgarten does not define 'positing' in his metaphysics but in his logic, implying that for him it has logical rather than strictly metaphysical significance: "What we judge as true, we posit; what as false, we

\footnotetext{
${ }^{55}$ If one posits relatively that wombats are furry, and then absolutely that wombats exist, one can posit furry things absolutely (that they exist) as well as posit that existing wombats are (also) furry, i.e. posit furry wombats absolutely. Although Timothy Rosenkoetter presents a similar view, I do not (for reasons that I cannot explicate here) agree with him that relative positing is dependent on absolute positing so that "['God is omnipotent'] is properly analysed as [...] 'If God is, then omnipotence is"” (Rosenkoetter, Timothy: “Absolute Positing, the Frege Anticipation Thesis, and Kant's Definition of Judgment.” European Journal of Philosophy vol. 18, 2008, 547).
} 
cancel" $^{56}$. Baumgarten does not connect positing to being or differentiate between relative and absolute positing. Even had he recognised this connection, he could not have applied his definition of positing to existence, for it would at best achieve this, quite uninformative result: when we posit that $A$ exists, we judge " $\mathrm{A}$ is" to be true. By binding positing to truth of judgments Baumgarten's definition is not suitable for concepts and existence of their objects. Only by following Kant in defining positing in general as being and distinguishing between relative positing in the judgment " $\mathrm{A}$ is B" (Baumgarten's 'positing') and absolute positing of $A$ in "A is" could existence be defined via positing without making it into just another predicate.

Here Kant does something quite elegant: he takes one of the most fundamental concepts of Baumgarten's elaborate system, recognises its intimate connection to the very concept of being that Wolff left unclear and Baumgarten sought in vain to define, and uses it to redefine existence. This betrayed the lack of any grip on existence in Baumgarten's system: it was exposed as mere self-contained spinning in the logical void deprived of a demonstrable relation to the existing things that are the proper subject matter of metaphysics.

Arguably, when metaphysics finally catches traction again, it is within Kant's critical framework and transcendental idealism. It seems not to have dawned upon Kant until later that - having rejected Baumgarten's suggestion - he needed a criterion of existence to complement his definition of it as absolute positing: on what grounds we may posit things. In the Critique existence became a modal category, the principle for the cognition of which Kant presents in the Postulates of Empirical Thinking in General: we cognise existence by experiencing or perceiving the thing $a$ as instantiating the properties $A_{I}$. This is the postulate of actuality: "That which is connected with the material conditions of experience (of sensation) is actual." ${ }^{, 57}$ Or, more clearly:

The postulate for cognizing the actuality of things requires perception [...] - not immediate perception of the object itself [...] but still its connection with some actual perception in accordance with the analogies of experience $[\ldots] . .^{58,59}$

\footnotetext{
56 "Quae vera iudicamus, ponimus; quae falsa, tollimus" (Baumgarten, A. G.: Acroasis logica in Christianum L. B. de Wolff. Halle \& Magdeburg, 1761, §151).

${ }^{57} \mathrm{KrV}$, A 218/B 265.

${ }^{58} \mathrm{KrV}$, A $225 / \mathrm{B} 272$.
} 
Indeed, although Kant's theory of existence is often sought in the Only Possible Ground and in the Transcendental Ideal, it is also explicit in the Postulates. What is more, there the special status of existence is grounded on the "peculiarity" of all modal categories ${ }^{60}$ :

The categories of modality have this peculiarity: as a determination of the object they do not augment the concept to which they are ascribed as predicates in the least [...]. No further determinations in the object itself are hereby thought[.] ${ }^{61}$

Kant also adds the already cited ( $\mathrm{KrV}$, A 234-5/B 287 n.) claim in opposition to Baumgarten: "Through the actuality of a thing I certainly posit more than possibility, but not in the thing; for that can never contain more in actuality than what was contained in its complete possibility." Neither the concept of an object nor the object itself gets added a determination (real predicate) when any of the modal concepts of possibility, actuality/existence or necessity are applied. ${ }^{62}$ Ascribing the modality $M$ to the concept $A=\left\{\mathrm{A}_{1}, \ldots, \mathrm{A}_{\mathrm{n}}\right\}$ does not amplify the set $A_{I}$ into $\left\{\mathrm{A}_{1}, \ldots, \mathrm{A}_{\mathrm{n}}, \mathrm{M}\right\}$, but determines whether and how A refers to objects: whether the set of predicates $A_{I}$ could be instantiated, is instantiated, or must be instantiated - or whether the extension $A_{E}$ possibly, actually, or necessarily has members. ${ }^{63}$ To say that modality - and hence

\footnotetext{
${ }^{59}$ Similarly, when existence is missing from my concept, "something is still missing in the relation of my entire state of thinking [thought of a thing], namely that the cognition of this object should also be possible a posteriori" (KrV, A 600/B 628).

${ }^{60}$ Cf. Heidegger, Martin: "Kants These über das Sein”, in: M. Heidegger: Wegmarken. Frankfurt am Main, 2004 [1961]. Röd, Wolfgang: "Existenz als absolute Position.” In: G. Funke \& T. Seebohm (eds.), Proceedings: The Sixth International Kant-Congress. Washington D.C., 1989. Longuenesse, Béatrice: Kant and the Capacity to Judge. Princeton, 1998.

${ }^{61} \mathrm{KrV}$, A 219/B 266, my emphasis, translation altered.

${ }^{62}$ According to Kant the modal concepts "are not at all determinations of a thing, or synthetic predicates" (Mron, AA 29: 821), and adds that "we must nevertheless concede that all concepts, modal concepts as well, can be made into predicates, but not into real predicates or determinations, but rather logical ones, e.g., God is possible" (Mron, AA 29: 822). Cf. V-Met-L2/Pölitz, AA 28: 554.

${ }^{63}$ Sometimes it is said that modality (including existence) denotes a second-order predicate (e.g. Wolff, Michael: Die Vollständigkeit der kantischen Urteilstafel. Frankfurt, 1995, 128. Forgie, William J.: "Kant and Frege: Existence as a Second-Level Property". Kant-Studien vol. 91, 2000, 165-177. Rosenkoetter, Timothy: “Absolute Positing, the Frege Anticipation Thesis, and Kant's Definition of Judgment." European Journal of Philosophy vol. 18, 2009, 548-50). Although I have some
} 
existence - does not add to the content of the thing is simply to say that the instantiated set $A_{I}$ is identical in all cases.

Finally, since Kant's positive definition and criterion of existence are grounded already in the Postulates of the Transcendental Analytic, he can justify absolute positing as the definition and perception as the criterion of existence without recourse to his negative theses (E1-)-(E3-), laid down in the Transcendental Dialectic. As Daniel Bonevac notes, it is therefore crucial that "any attempt to challenge Kant's refutation [of the ontological proof] must attack the foundations of the critical program" ${ }^{\prime 64}$. That Kant's argument runs from existence as positing to the negative theses, rather than vice versa, is crucial for avoiding circular argumentation in the Transcendental Ideal. It also makes him less vulnerable to alternative formulations of the thesis that existence is a predicate, ${ }^{65}$ since his critique of the view is not based on the negative thesis that some formulations are insufficient (particularly Baumgarten's) but on his positive theory of what existence is. And this positive definition of being as positing stands on its own two feet, grounded in reflection on the word 'is', in Kant's elaborate semantics, and in the recognition that the pivotal yet inadequately defined term 'positing' of Baumgarten's ontology is identical to being so that relative positing corresponds to the copula in " $\mathrm{A}$ is $\mathrm{B}$ " and absolute positing to the existential 'is" in " $\mathrm{A}$ is".

\section{Conclusion}

Throughout his works, Kant engages in a profound and meticulous critique of the Wolffian-Baumgartenian notion of existence as the complement of possibility. This is not easy to spy from Kant's text, for he seldom mentions Wolff or Baumgarten as the

\footnotetext{
reservations about the accuracy of this characterisation, especially when it is taken to be essentially the same as Frege's second-level concept reading of existence, I will reserve a discussion of it for a later time.

${ }^{64}$ Bonevac, Daniel: "Kant on Existence and Modality." Archiv für Geschichte der Philosophie vol. 64, $1982,300$.

${ }^{65}$ This is especially true of Leibniz, who can be seen as avoiding Kant's direct criticism of Wolff and Baumgarten (Nachtomy, Ohad: "Leibniz and Kant on Possibility and Existence." British Journal for the History of Philosophy, 2012).
} 
target of his criticism - probably because his audience was familiar with the dominant views of the time. Although he ultimately holds almost the opposite views to Baumgarten, Kant is in a sense not very far from Baumgarten. Kant's terminology is Baumgartenian with its determinations, positings, and thoroughgoing determinations. And although Kant agrees to an extent on Baumgarten's criterion, classification, and definition of existence, he rejects them in favour of a definition of existence as absolute positing. Kant's many-faceted reasoning can be made clear only in connection with and in contrast to Baumgarten: existence cannot be grounded on thoroughgoing determination, because existence is not one of the determinations, since it adds nothing to the content of a thing, for it rather posits the thing itself along with the determinations it contains. The argument runs from the positive definition of existence as absolute positing to the negative ones, not vice versa.

Thus one might question the widespread notion that Kant is so far removed from his rationalist predecessors as to be almost incommensurable with them. Rather, to a great extent Kant corrects (and eventually undermines) Baumgarten's system from within. For Kant, Wolff's definition of existence as complementum possibilitatis is hopelessly vague and Baumgarten's attempt to specify it ultimately a failure. Kant picks up on Baumgarten's inadequate definition of positing. One can posit in two ways, either relatively in "A is B" or absolutely in "A is" or "A exists." Since no amount of relative positing or adding predicates to the subject term will contribute to the absolute positing or existence of something as the referent of the subject term, Baumgarten's definition of existence as complementum possibilitatis is bound to fail. Having thus lost all clear connection to existence, the rationalistic Schulmetaphysik stood in dire need of justification - delivered by Kant in the Critique of Pure Reason, along with its transcendentally idealistic revisions of and restrictions to ontology.

Finally, although due to the confines of this article the elaboration of this point must wait for a future occasion, this view of existence suggests the hypothesis that certain central metaphysical and existence related theses of rationalism - namely those of rational psychology, cosmology, and theology - are inherently flawed. Thus the great leap to transcendental idealism might not be required to drive Kant's critique home; rather one could see transcendental idealism as the necessary saving grace of (scientific) metaphysics that Kant envisioned it to be. Indeed, Kant's criticism of his predecessors' notion of existence remained essentially the same after 1763 and was thus commenced and developed years before transcendental idealism and so remains 
independent of the latter. Thus I hazard a more speculative concluding remark and hypothesise that perhaps Kant's philosophy of existence and his critique of his predecessors' notion of it for its part set him on the path towards transcendental idealism and critical philosophy in the first place - a remark to be substantiated on another occasion. 